\title{
Indigenous knowledge of dye-yielding plants among Bai communities in Dali, Northwest Yunnan, China
}

\author{
Yanxiao Fan ${ }^{1,3}$, Yanqiang Zhao ${ }^{2}$, Aizhong Liu ${ }^{1,3,4}$, Alan Hamilton ${ }^{3}$, Chuanfa Wang ${ }^{1}$, Liangqun Li ${ }^{3}$, Yekun Yang ${ }^{4}$ \\ and Lixin Yang ${ }^{1,3,4^{*}}$
}

\begin{abstract}
Background: Bai people in the Dali Prefecture of Northwest Yunnan, China, have a long history of using plant extracts to dye their traditional costumes and maintain this culture for posterity. However, the development of modern technology, while vastly improving the dyeing efficiency, is also replacing indigenous knowledge which threatens the indigenous practice, causing the latter disappearing gradually. This study sought to examine the indigenous knowledge of plants used for textile dyeing in Bai communities, so as to provide a foundation for their sustainable development.
\end{abstract}

Methods: We conducted a semi-structured interview among 344 informants (above age 36) selected through a snowball sampling method. Free lists and participant observation were used as supplementary methods for the interviews. Three quantitative indicators (informant consensus factor [ICF], use frequency, and cultural importance index [CI]) were used to evaluate the indigenous knowledge of the dye-yielding plants.

Results: Twenty-three species belonging to 19 plant taxonomic families were used for dye by Bai communities. We summarized them into four life forms, eight used parts, five colors, three processing methods, and four dyeing methods. Among them, Strobilanthes cusia (Nees) O. Kuntze was the most traditional dyeing plant and has an important cultural value. Location, age, and gender were found to have a significant effect on indigenous knowledge, and the dyeing knowledge was dynamic and influenced by social factors.

Conclusions: Diverse plant resources and rich indigenous knowledge of textile dyeing persist at settlements of Bai communities in Dali Prefecture. However, high labor costs and thinning market of traditional products that use plant dye cause repulsion toward traditional practice. To that, a good income in other profession attracts indigenous people to shift from their tradition of making plant-based dye and associated cultural systems at risk of extinction. More research for market development for products that use plant-based dye is necessary for the conservation of this valuable knowledge and biodiversity protection in Bai communities.

Keywords: Indigenous knowledge, Dye-yielding plants, Bai communities, Biodiversity protection

\section{Background}

Before the discovery of synthetic dyes by William Henry Perkin in 1856, dyes obtained from plants were in use all over the world. Afterward, synthetic dyes, with low cost, plentiful colors, and easy access, gradually replaced natural plant dyes. Nowadays, with increasing realization

\footnotetext{
* Correspondence: rattan@mail.kib.ac.cn

'Southwest Forestry University, Kunming 650224, Yunnan, China

${ }^{3}$ Key Laboratory of Economic Plants and Biotechnology, Kunming Institute of Botany, Chinese Academy of Sciences, No. 132 Lanhei Road, Kunming 650201, China

Full list of author information is available at the end of the article
}

that some synthetic dyes can be harmful to health and the environment [1-3], there is renewed interest in natural dye-yielding plants [4]. Furthermore, due to the severe threat of ecological globalization, environmental degradation, and cultural homogenization, it is crucial to record the indigenous knowledge of plant utilization and preserve the plants' habitats, especially where they are not yet completely lost [5].

In China, few ethnobotanical research on dye derived from plants has been carried out among ethnic groups, such as Dai, Buyi, Miao, Yao, Zhuang, Dong, Li, and 
Weiwuer [6-12]. However, these studies represent only a few ethnic groups of China whose indigenous knowledge is disappearing. Among these ethnic groups, Bai is a special group with abundant indigenous dyeing knowledge, and no research on dyeing plant has been investigated among this group.

With the population of 1.93 million, Bai is the 15th largest ethnic group in China and one of the 25 ethnic groups in Yunnan. In this province, Dali Bai Autonomous Prefecture is home to $58 \%$ Chinese Bai population [13]. Historical studies show that the modern Bai ethnic group has emerged from an amalgam of ethnic groups, including the original inhabitants of Kunming, the Heman people around Erhai Lake, the Di people, and Qiang people from Qinghai-Tibetan Plateau. Therefore, traditional Bai culture contains not only cultural elements of Han and Tibetan but also its own characteristics $[14,15]$. For example, Bai people often use plant dyes to stain images of camellia flowers, pomegranate fruits, fishes, and butterflies in textile dyeing, which in Bai's culture are symbols of fertility, wealth, possessions, and good fortune [16-18].

This is the first ethnobotanical study focusing on Bai people's indigenous knowledge of plant-based dyes. The plant materials, used parts, dyeing methods, and uses are recorded, with data quantified. It provides a foundation for follow-up work to contribute to the maintenance of indigenous plant-dyeing knowledge and dyeing plant resources.

\section{Methods}

\section{Study sites in Dali Prefecture}

Dali Bai Autonomous Prefecture was selected for this research because it is both floristically rich and full of the cultural practice of drawing on biodiversity for dyeing. Located in the middle west of Yunnan Province (2441$2642^{\prime} \mathrm{N}, 9852-10103^{\prime} \mathrm{E}$ ), on the average, the elevation of this area is $2090 \mathrm{~m}$, annual precipitation received is $776 \mathrm{~mm}$, and annual temperature is $16.5^{\circ} \mathrm{C}$. This study area is the birthplace of the Bai, and likewise where Bai people are most densely settled. It is also regarded as the cultural and linguistic center by this ethnic group [19].

After consulting the local government officials and making preliminary field visits, for survey, we selected 13 traditional villages, five local markets, three relevant government agencies, and three local factories that uses plant-based dyes. The survey was conducted in five counties namely Dali, Weishan, Eryuan, Jianchuan, and Heqing which belong to the Prefecture (Fig. 1). Field research was carried out in the study sites between April 2016 and November 2017.

\section{Ethnobotanical surveys}

Prior to this study, locals were contacted and informed about the purpose of the study. Investigations were done based on their consent. Semi-structured interviews were carried out among indigenous people, and questions asked were as follows: (1) Which plants around the communities are useful in deriving natural dye? (2) Which parts of the plant are used? (3) What is the dye used for? (4) What color is the dye? (5) What are the methods of dye? (6) What customs or indigenous knowledge are linked with plant-based dyes? (7) Are there any other uses for these dye-yielding plants?

We used snowball sampling [20] method to select a total of 344 informants that include 197 men and 147 women (Table 1). The informants included farmers, cloth merchants, and indigenous people specialize on plant-based dyes who were aware about plant-based dye and indigenous practice of coloring using plant extracts.

We tabulated a recorded information about the plants (Table 2) that comprise voucher specimen code, Chinese name, scientific name, local name, family name, life form, used parts, color, main chemical components, and use frequency. We collected 1-2 voucher specimens for each species, adding up to 41 specimens in total, all deposited in the Herbarium, Kunming Institute of Botany, Chinese Academy of Sciences, and verified by the local Bai people, plant taxonomists, and experts from the authors' institution.

\section{Statistical analysis}

According to informants, each of the listed plant was used to extract one to three different colors. To determine the consistency of the information, we used the informant consensus factor (ICF) [21] which can be mathematically expressed as:

$$
\mathrm{ICF}=\frac{\mathrm{Nur}-\mathrm{Nt}}{\mathrm{Nur}-1}
$$

In this expression, Nur indicates the total number of plant species used to extract a certain color and Nt refers to the number of species simultaneously approved by all informants for dyeing a certain color. ICF values range between 0 and 1 , with 0 indicating the highest level of informant consent and 1 the lowest. To quantify the use frequency of certain species [22], the below formula was adopted:

$$
f=\frac{N_{m}}{N_{i}}
$$

In this formula, $f$ represents the use frequency, $N_{m}$ is the frequency of certain species mentioned by informants, and $N_{i}$ represents the total number of informants. The higher the value of $f$, the more frequently the plant is used. 


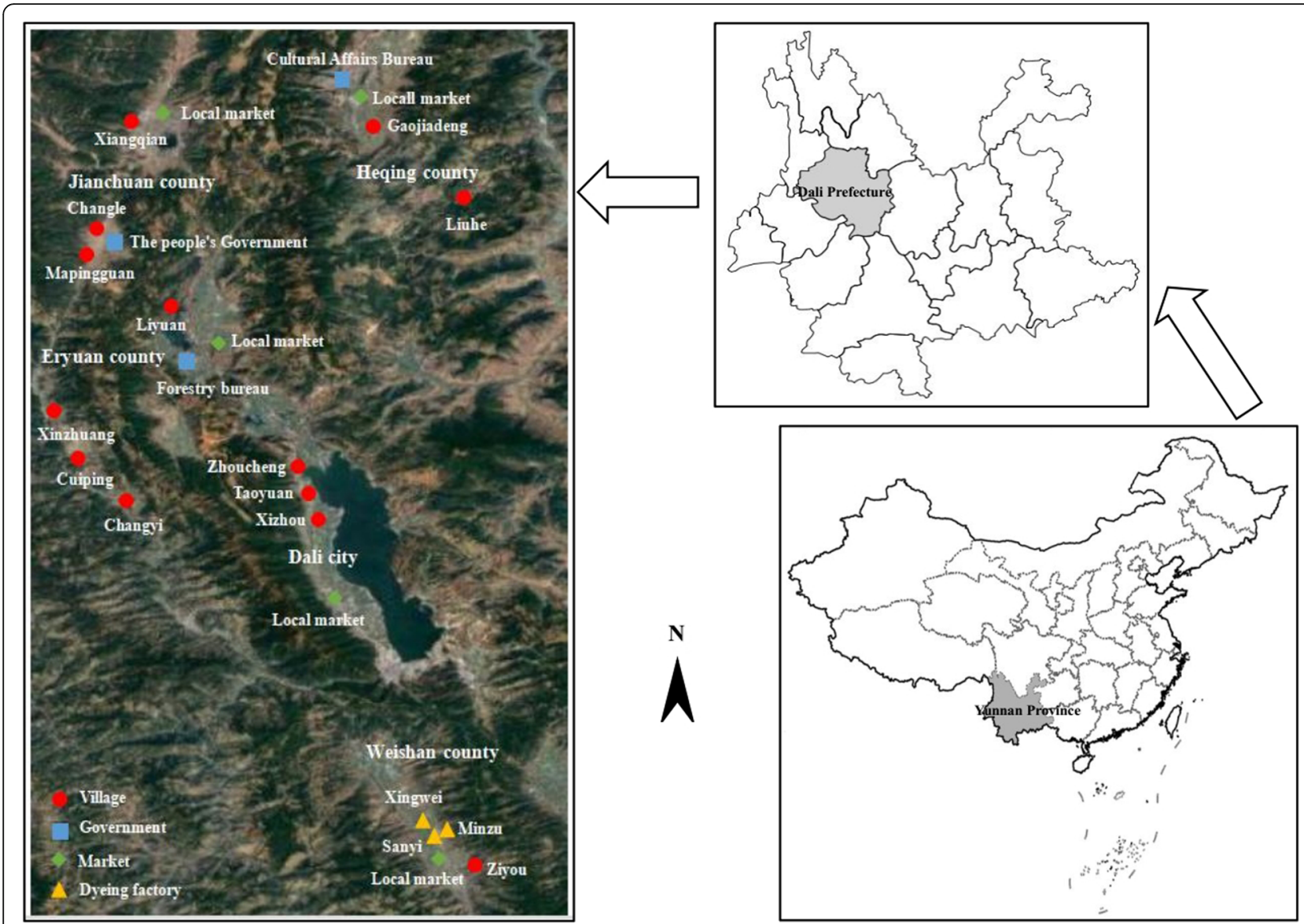

Fig. 1 Location map of study sites

Table 1 Demographic details of the informants

\begin{tabular}{llll}
\hline Category & Subcategory & Number & \% of informants \\
\hline Location & Weishan & 84 & 25 \\
& Daili & 46 & 13 \\
& Eryuan & 73 & 21 \\
& Jianchuan & 71 & 21 \\
& Heqing & 70 & 20 \\
Age & $36-45$ & 21 & 6 \\
& $46-55$ & 58 & 16 \\
& $56-65$ & 114 & 33 \\
& $66-75$ & 108 & 32 \\
& $76-85$ & 43 & 13 \\
Gender & Male & 197 & 57 \\
& Female & 147 & 43 \\
\hline
\end{tabular}

Also, the cultural importance index (CI) was calculated to evaluate the cultural significance of dye-yielding plants [23] using the formula below:

$$
\mathrm{CI}_{S}=\sum_{U=U_{1}}^{u_{\mathrm{NC}}} \sum_{i=i_{1}}^{i_{N}} \frac{\mathrm{UR}_{u i}}{N}
$$

$N$ is the total number of informants; $\mathrm{NC}$ is the total number of usages, for a given dye-yielding plant $S$; $\mathrm{UR}_{u i}$ represents a utilization report (UR) of species $S$ mentioned by the $i$ th informant in usage $u$; thus, the $\mathrm{CI}$ is the sum of the proportion of informants that mentioned each of the use purpose(s) of a given species. This index indicates the spread of use of each species and the diversity of its uses. Each purpose mentioned is significant to the importance of the plant. Therefore, more usages can result in higher $\mathrm{CI}$ value.

\section{Results}

The diversity of dye-yielding plants in Bai communities We documented a total of 23 species used by indigenous people to extract different colors that belong to 19 plant families. The majority recorded species were herbaceous (10), while the remaining were trees (7), shrubs (5), and 


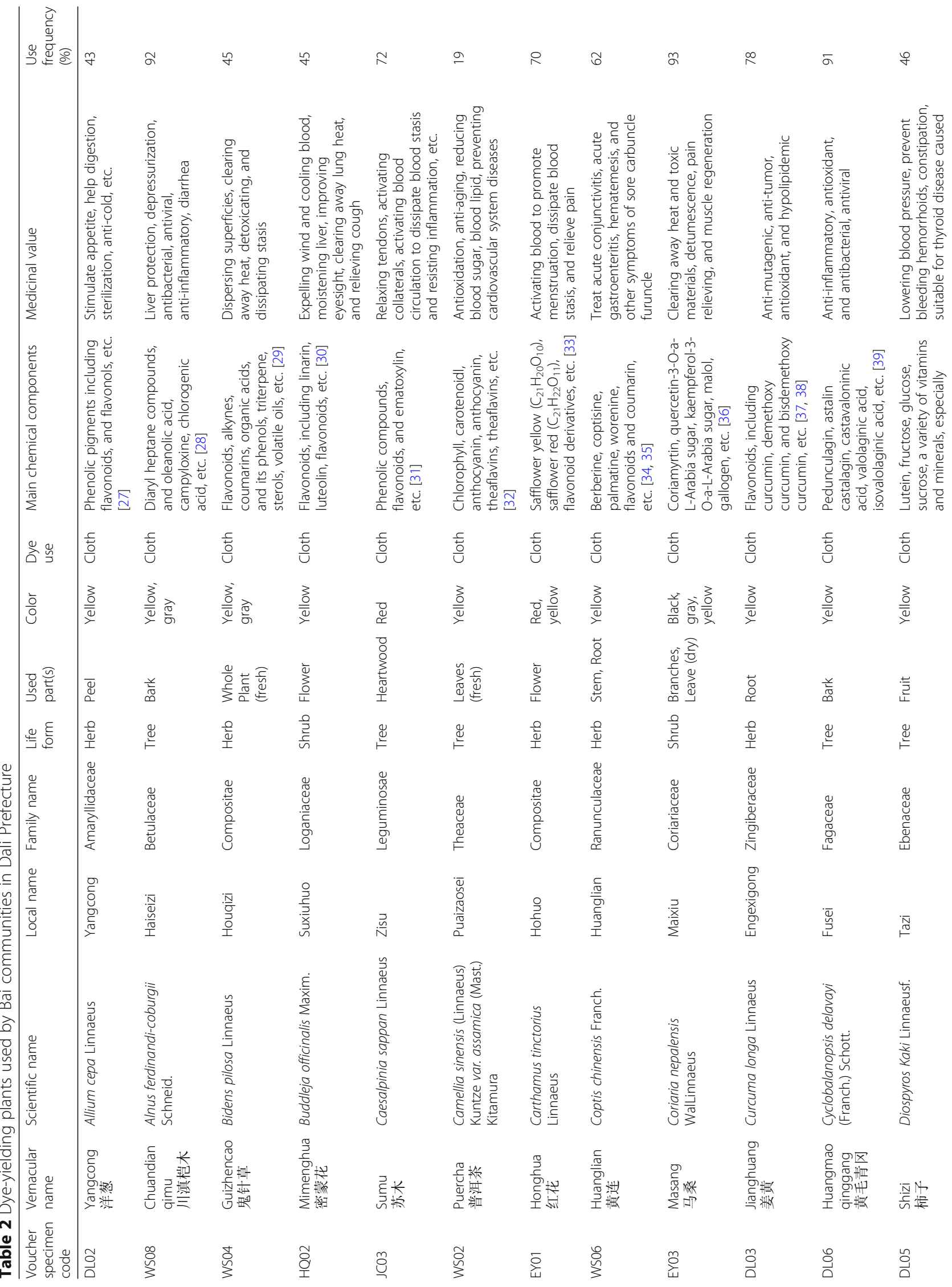


Fan et al. Journal of Ethnobiology and Ethnomedicine $\quad$ (2018) 14:74

Page 5 of 11

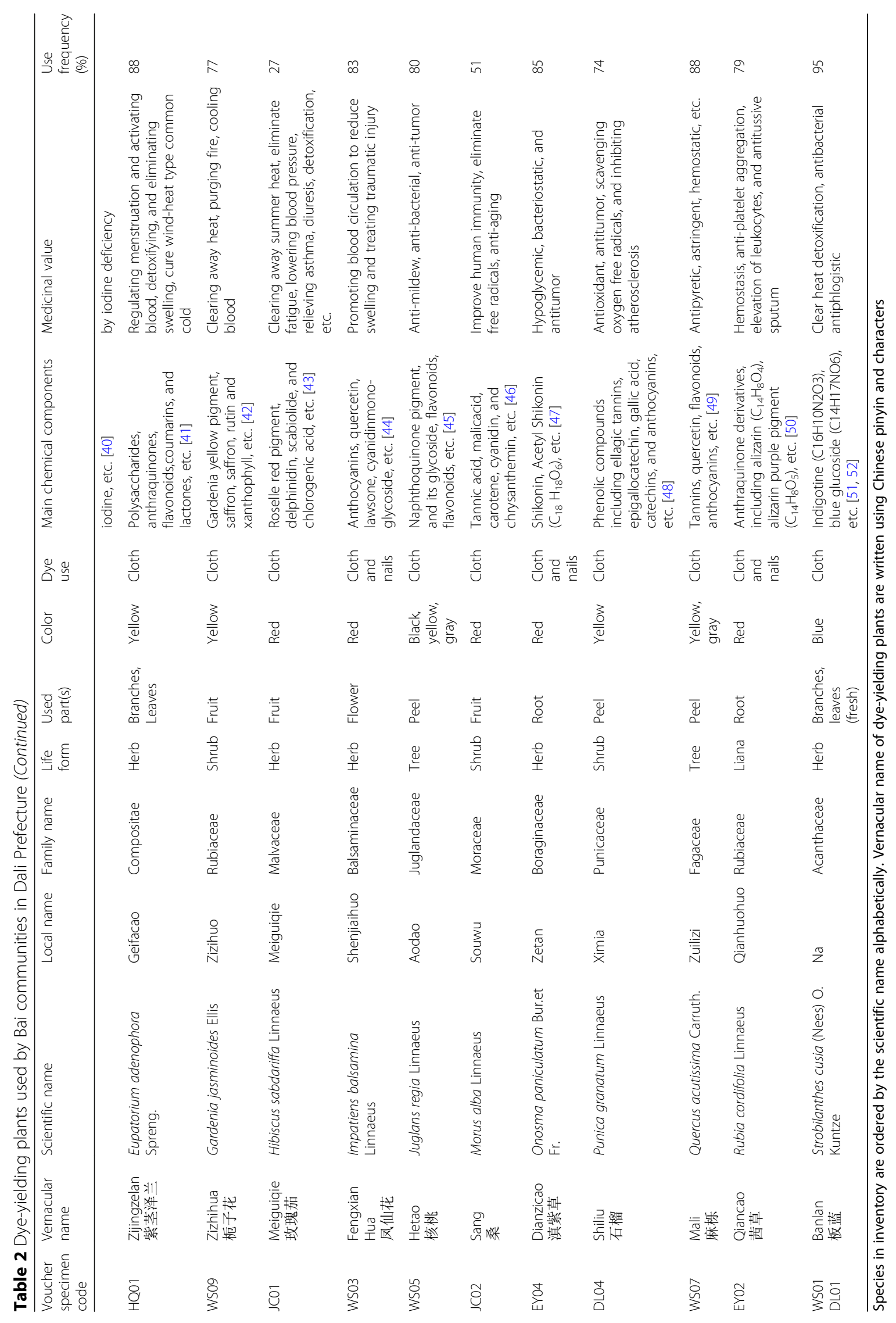


lianas (1). The plant parts used in extracting color include peel (4), fruit (4), leaves (4), roots (4), flowers (3), bark (3), heartwood (1), and the whole plant (1). Yellow (16), red (7), gray (5), black (2), and blue (1) extract were produced from the listed plants (Table 2). All the plants listed in Table 2 were used in textile dyeing process. In addition to that, species like Impatiens balsamina L., Onosma paniculatum Bur. et Franch., and Rubia cordifolia L. were also used for coloring nails. Informants mentioned that these plants were also used by Bai people as source of food, medicine, and ornaments, beside extracting color.

Indigenous knowledge dynamics in location, age, and gender Data analysis reveals significant regional differences in the distribution of indigenous knowledge of plant-based dyes. Out of total informants, $25 \%$ belong to Weishan, $21 \%$ from Eryuan, 21\% from Jianchuan, 20\% from Heqing, and 13\% from Dali (Table 1). Bai people in Dali have the tradition of preparing and selling product colored with plant-based dyes. During survey, we noticed still it was a source of income for local inhabitants, and hence, the culture of using plant-based dye was still alive. Therefore, enough information was obtained by interviewing a few people in Dali. In contrast to Dali, we noticed that Heqing, Jianchuan, Eryuan, and Weishan were highly influenced by the other income-generating opportunities developed along with the local economy; hence, only a few elderly people (especially male), who were knowledgeable, are still using the plant-based dye.

The age difference among the informants was also noticeable: $22 \%$ of informants were 36 to $55,65 \%$ were aged 56 to 75 , and $13 \%$ were 76 and 85 . It was clear that older people possessed good knowledge of plant-based dye, while the knowledge decline with younger generation. We noticed that the informants themselves were also aware of this truth. According to them, young people were not willing to get involved in traditional textile dyeing as it is a strenuous activity, and migrating from rural to urban area in search of jobs and different lifestyle.

Moreover, $57 \%$ of the informants are male and $43 \%$ are female (Table 1); gender role is clearly defined in the traditional textile dyeing profession. According to the informants, men were involved in the collection of plants, the preparation of dyes, and the process of dyeing fabric that requires certain physical strength. Women were mainly responsible for cutting fabrics, designing patterns, and some time-consuming work. As a result, men generally possessed more knowledge about dye-yielding plants and plant collection sites compared to women.

\section{Evaluation of indigenous knowledge on dye-yielding plants}

Three quantitative indicators [ICF (Table 3), $f$ (Table 2), and CI (Table 4)] were selected to evaluate 23 species of
Table 3 Informant consensus factor of dye-yielding plants used by Bai people

\begin{tabular}{llll}
\hline Color & $\begin{array}{l}\text { Total number of } \\
\text { plant species (Nur) }\end{array}$ & $\begin{array}{l}\text { The simultaneous } \\
\text { utilized number of } \\
\text { plant species (Nt) }\end{array}$ & ICF \\
\hline Blue & 1 & 1 & 0.00 \\
Gray & 5 & 4 & 0.25 \\
Red & 7 & 5 & 0.33 \\
Yellow & 16 & 11 & 0.33 \\
Black & 2 & 1 & 1.00 \\
\hline
\end{tabular}

dye-yielding plants. These indicators showed different ranking of species indicating that the uses of the dye-yielding plants were multiple and the distribution of staining knowledge among informants was dissimilar.

\section{ICF values}

Informants mentioned the use of five different colors, viz. blue, gray, red, yellow, and black. The results of the ICF showed the highest value for black (1), followed by yellow, red, and gray, with values $0.33,0.33$, and 0.25 respectively, while blue had the lowest ICF values (0.00). These distinct ICF values indicated that informants reached different consensus with regard to different color categories. Blue is primarily extracted from Strobilanthes cusia (Nees) O. Kuntze, which was widely agreed among informants. Plants that produce black were mainly Juglans regia L. and Coriaria nepalensis Wall.. Juglans regia L. was more common. In addition, the ICF values of the other three categories were less than 0.5 , indicating that the plants used for extracting gray, red, and yellow were not very different.

\section{Use frequency}

The use frequency of Strobilanthes cusia (Nees) O. Kuntze, Impatiens balsamina L., Juglans regia L., Quercus acutissima Carruth., Cyclobalanopsis delavayi (Franch.) Schott., Alnus ferdinandi-coburgii Schneid., Coriaria nepalensis Wall., Onosma paniculatum Bur. et Franch., and Eupatorium adenophora Spreng. were all over 80\%, and Carthamus tinctorius L., Coptis chinensis Franch., Curcuma longa L., Rubia cordifolia L., Morus alba L., Punica granatum L., Caesalpinia sappan L., and Gardenia jasminoides Ellis were all with use frequency of more than $50 \%$. Some of these plants were harvested from wild in Dali Prefecture, and some were cultivated. The wide use of listed plants did not affect the local ecological settings. Camellia sinensis (L.) O. Kuntze var. assamica (Mast.) Kitamura, Bidens pilosa L., Allium cepa L., Hibiscus sabdariffa L., Diospyros kaki Thunb., and Buddleja officinalis Maxim. had a low use frequency $(<50 \%)$. According to the informants, the economic and medicinal value of these plants was significantly higher than dye, so Bai people only 
Table 4 Cultural importance index of dye-yielding plants used by Bai people

\begin{tabular}{|c|c|c|c|c|c|}
\hline \multirow[t]{2}{*}{ Scientific name } & \multicolumn{4}{|c|}{ Use purposes } & \multirow[t]{2}{*}{$\mathrm{Cl}$} \\
\hline & Dye & Food & Medicine & Others & \\
\hline Strobilanthes cusia (Nees) O. Kuntze & 328 & 103 & 337 & $153(\mathrm{OR})$ & 2.67 \\
\hline Punica granatum L. & 253 & 344 & 73 & $213(\mathrm{OR})$ & 2.57 \\
\hline Gardenia jasminoides Ellis & 264 & 25 & 298 & $269(\mathrm{OR})$ & 2.49 \\
\hline Morus alba L. & 177 & 344 & 275 & & 2.31 \\
\hline Juglans regia L. & 274 & 344 & 112 & & 2.12 \\
\hline Diospyros Kaki L.f. & 159 & 344 & 57 & $83(\mathrm{OR})$ & 1.87 \\
\hline Cyclobalanopsis delavayi (Franch.) Schott. & 312 & & 261 & $64(\mathrm{FI})$ & 1.85 \\
\hline Curcuma longa $\mathrm{L}$. & 269 & 46 & 243 & $73(\mathrm{OR})$ & 1.83 \\
\hline Impatiens balsamina $\mathrm{L}$. & 287 & & 143 & $174(\mathrm{OR})$ & 1.76 \\
\hline Carthamus tinctorius $\mathrm{L}$. & 241 & & 313 & & 1.61 \\
\hline Coptis chinensis Franch. & 212 & & 317 & & 1.54 \\
\hline Allium cepa $\mathrm{L}$. & 149 & 344 & 9 & & 1.46 \\
\hline Onosma paniculatum Bur. et Fr. & 291 & & 197 & & 1.42 \\
\hline Caesalpinia sappan Linn. & 247 & & 211 & & 1.33 \\
\hline Rubia cordifolia L. & 271 & & 179 & & 1.31 \\
\hline Hibiscus sabdariffa Linn. & 93 & 76 & 274 & & 1.29 \\
\hline Alnus ferdinandi-coburgii Schneid. & 317 & & 84 & $41(\mathrm{Fl})$ & 1.28 \\
\hline Coriaria nepalensis Wall. & 321 & & 39 & $\begin{array}{l}46(\mathrm{FI}) \\
23(\mathrm{FE})\end{array}$ & 1.25 \\
\hline Quercus acutissima Carruth. & 301 & & 33 & $78(\mathrm{Fl})$ & 1.20 \\
\hline Eupatorium adenophora Spreng. & 301 & & 16 & $12(\mathrm{FE})$ & 0.96 \\
\hline Buddleja officinalis Maxim. & 154 & 21 & 47 & & 0.65 \\
\hline Bidens pilosa $\mathrm{L}$. & 156 & & 27 & $8(\mathrm{FE})$ & 0.56 \\
\hline Camellia sinensis (L.) Kuntze var. assamica (Mast.) Kitamura & 65 & 39 & 13 & $21(\mathrm{OR})$ & 0.40 \\
\hline
\end{tabular}

Ranked by $\mathrm{Cl}$ values from high to low

$O R$ ornamental, Fl firewood, FE fertilizer, $C l$ cultural importance index

used these plants to stain some high-grade silk products or some non-selling exhibits.

\section{Cl values}

Strobilanthes cusia (Nees) O. Kuntze (2.67), Punica granatum L. (2.57), Gardenia jasminoides Ellis (2.49), Morus alba L. (2.31), Juglans regia L. (2.12), Diospyros kakiThunb. (1.87), Cyclobalanopsis delavayi (Franch.) Schott. (1.85), Curcuma longa L. (1.83), Impatiens balsamina L. (1.76), Carthamus tinctorius L. (1.61), and Coptis chinensis Franch. (1.54) showed higher CI values. High CI values may indicate that the informants were very familiar with the plants and their uses and that the plants had high cultural importance in the community. Camellia sinensis (L.) O. Kuntze var. assamica (Mast.) Kitamura (0.40), Bidens pilosa L. (0.56), Buddleja officinalis Maxim. (0.65), and Eupatorium adenophora Spreng. (0.96) showed low CI values, which probably means that these plants had few or no other uses besides use in dyeing or that few informants knew other uses.
These plants can be of special importance to certain informants.

\section{Dye-yielding plants and related indigenous knowledge Harvest time}

Harvest time of dye-yielding plants depends on the growth cycle. For example, Bai harvest Strobilanthes cusia (Nees) O. Kuntze leaves and stems before flowering, usually between August and October, when the pigment content in the plant reaches the highest.

\section{Dye-making}

According to the informants, method varied of dye-making depending upon the source plant material; however, it can be summarized into three main methods: water extraction, fermentation, and mashing. For water extraction, plants were thoroughly washed and useful parts were mashed or cut and then soaked in either hot or cold water for extraction with occasional stir. After (certain time), the mixture was squeezed and filtered to 
obtain the required solution containing extract. Informants mentioned that the fermentation method is relatively complicated and commonly used in the production of Strobilanthes cusia (Nees) O. Kuntze dye. It is necessary to soak the fresh leaves and stems of Strobilanthes cusia (Nees) O. Kuntze in the cask to make them ferment, and it is important to keep the leaves and stems remained submerged under water. Sometimes, additional pressure is required to fully dissolve the indigo component in water. Informants mentioned that foam formation on the surface of the water needs to be checked carefully, which means fermentation process is ongoing (Fig. 2). Turning of plant part into red indicated the completion of fermentation process. Mashing is usually used for direct nail coloring.

\section{Dyeing method}

We documented four different types of dyeing method depending on the mordant used and the order of adding: (1) direct dyeing, which means dyeing without mordant; (2) pre-mordant dyeing where the fiber is soaked in mordant before dyeing; (3) post-mordant dyeing, which entails soaking fiber material with a mordant after plant dyeing; and (4) co-bath dyeing which involves mixing both dyeing mordant and solution together. This method is most popular in Bai communities.

\section{Mordant}

Informants mentioned that the plant dyes were unstable and easy-fading; therefore, Bai people used some natural mordant to improve their color-fast. Acid mordant (chaenomeles fruit vinegar, black plum juice, lemon juice, etc.), alkaline mordant (plant ash, lime, etc.), and metal mordant (natural minerals) were commonly used. The kind and amount of mordant affect the color of the plant-dyed fabric. For example, Rubia cordifolia L. gives the fabric a yellow color when acid mordant chaenomeles fruit vinegar and black plum juice were used to fix

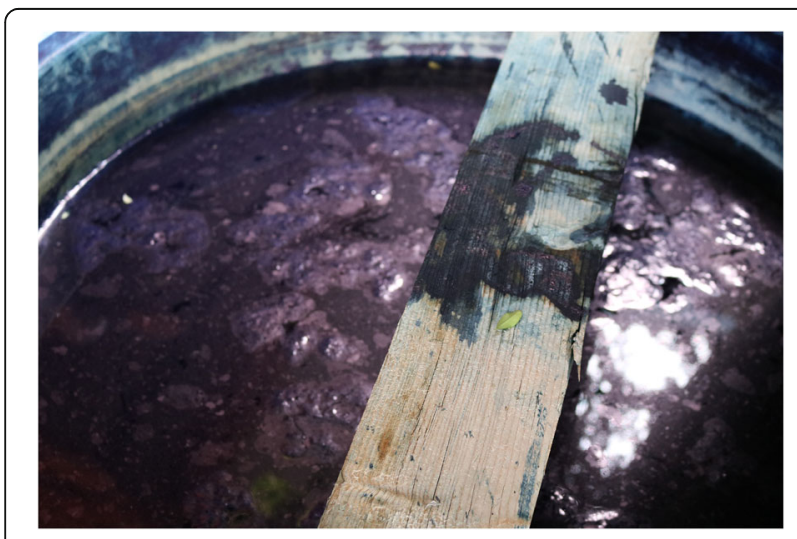

Fig. 2 The fermentation of Strobilanthes cusia (Nees) O. Kuntze the dyes, and red with alkaline mordant. With different mordant quantity, the color varies: small amount induce weak acidity and alkalinity, producing a light color, while large amount generate dark color. Bai people are always known to choose the right type and amount based on their experience to acquire the desired color in dyeing.

\section{Traditional process of plant-dyeing cloth}

Bai people in Ziyou, Zhoucheng, and Xizhou villages have a unique dyeing technique called tie-and-dye that includes six steps. The first step of tie-and-dye was to design a pattern on a film of plastic. The second was to drill a series of holes along the pattern lines. Later, a cloth was laid under the plastic board, and with a brush dipped with mixed iodine pigment, the board was brushed back and forth. Then, using different needle techniques, they suture the cloth according to the printed pattern. This step is called Zahua in Bai language (Fig. 3). Afterward, the tied cloth was repeatedly dip-dyed in Strobilanthes cusia (Nees) O. Kuntze dye extract. People using indigenous technique made sure that the cloth got full contact with air to oxidized, so that the pigment get better fixed on the cloth. Finally, after drying the dyed cloth, stitches were removed and washed for the last time for inspecting the final product.

Strobilanthes cusia (Nees) O. Kuntze (blue dye) was an essential part of tie-and-dye and often mixed with white which we noticed was the favorite color of Bai people; hence, cloths dyed in this way were blue and white (Fig. 4). Due to its importance in traditional culture, Bai people also cultivated Strobilanthes cusia (Nees) O. Kuntze in their courtyard (Fig. 5).

\section{The custom of fingernail plant-dyeing}

Every year before their traditional Torch Festival, Bai women use plants to dye their fingernails in bright red. It is mainly for praising women's quality of loyalty. The custom has persisted since Tang Dynasty (618-907 CE) [24, 25].

Three plant species namely Rubia cordifolia L., Onosma paniculatum Bur. et Franch., and Impatiens balsamina L. were used by Bai people to stain their nails. Species used in different regions were varied. Bai people in Dali and Weishan often dye their nails with the flower of Impatiens balsamina L. while in Eryuan, Jianchuan, and Heqing, the roots of Rubia cordifolia L. and Onosma paniculatum Bur. et Franch. were commonly used. Bai people usually stain their fingernails in spare nights before the Torch Festival. They crushed fresh flower of Impatiens balsamina L. or root of Rubia cordifolia L. or Onosma paniculatum Bur. et Franch. in proper amount of chaenomeles fruit vinegar juice and put the mixture on nails. They then wrap the nails with leaves and wait for the nails to be stained bright red overnight. 


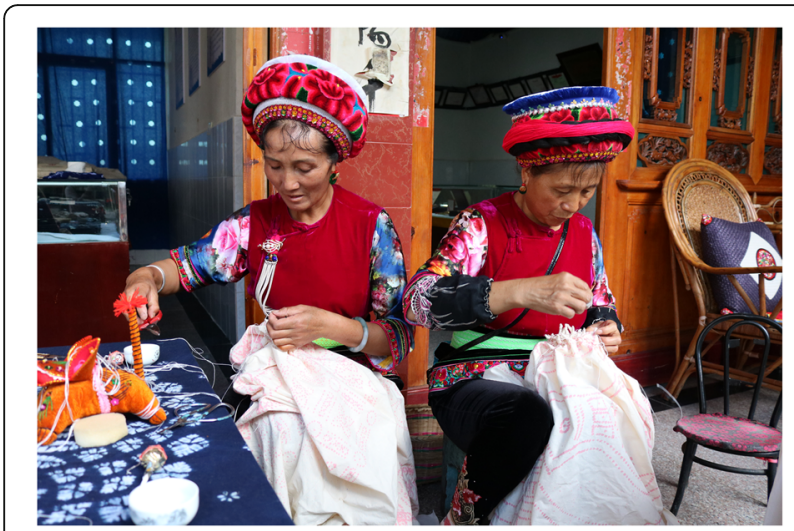

Fig. 3 One of the steps of the Bai tie-and-dye Zahua

\section{Indigenous knowledge developed in practice}

It was observed that indigenous knowledge of plant dyeing developed in the practice. For instance, Eupatorium adenophora Spreng. was originally an invasive plant which has brought many adverse effects to the development of local agriculture and animal husbandry. In the course of eradication, the local people accidentally found that Eupatorium adenophora Spreng. juice stained the skin and clothes that cannot be removed easily. Therefore, Bai indigene, with rich plant-dyeing experience, began to explore Eupatorium adenophora Spreng. as a potential dye, exploring its value and reducing its harm through continuous practice. Extraction of pigments from fresh stems and leaves of Eupatorium adenophora Spreng. with boiling water and dyeing after filtration was selected to be the most effective staining method. Nowadays, local dyeing factories in Dali had industrialized the application of Eupatorium adenophora Spreng. Bai people used their indigenous knowledge to turn harmful invasive plants into valuable ones.

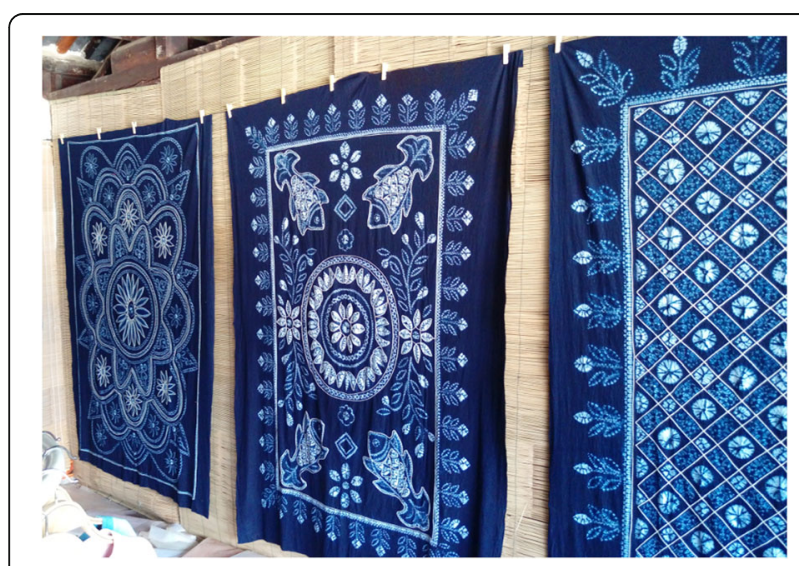

Fig. 4 Cloth dyed by Strobilanthes cusia (Nees) O. Kuntze

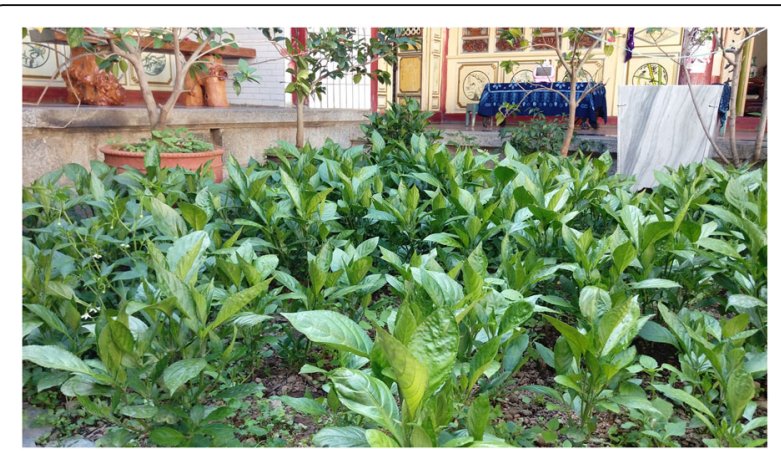

Fig. 5 Planting Strobilanthes cusia (Nees) O. Kuntze in the yard in Bai communities, Zhoucheng village, Xizhou town, Dali city

\section{Discussion}

Out of 23 dye-yielding plants used by Bai, Strobilanthes cusia (Nees) O. Kuntze is well known among the local people due to the tradition of tie-and-dye and already industrialized in as early as the Republic of China (1912-1949) [26]. In contrast to that, Eupatorium adenophora Spreng., Coriaria nepalensis Wall., Alnus ferdinandi-coburgii Schneid., Cyclobalanopsis delavayi (Franch.) Schott., and Quercus acutissima Carruth. are for the first time recorded as dye-yielding plant in Bai communities of Dali Prefecture. The plants used are diverse and are constantly enriched in dyeing practice among Bai communities.

However, the inheritance of indigenous knowledge of plant-based dye is facing some challenges because many of the knowledgeable person in dye processing in Bai communities are aged and chemical dyes are gradually taking the place of plant dyes. At the same time, high labor cost of plant dyes and low production plant dyes are placed onto a disadvantageous position in its competition with chemical dyes. Besides, economic development brings more working opportunities in other professions, which attracts local people to shift from traditional careers to new ones, risking the popularity of traditional plant-dyeing craftsmanship and its supporting cultural system.

To retain the tradition of plant-based dye, local dyeing factories in Dali Prefecture began to incorporate some plant used on small scale into industrial production. After continuous attempts, the dyeing processes of Eupatorium adenophora Spreng., Coriaria nepalensis Wall., Alnus ferdinandi-coburgii Schneid., Cyclobalanopsis delavayi (Franch.) Schott., and Quercus acutissima Carruth. became developed and have attained initial commercialization in the local dyeing factories. During field survey, the factories that we studied are Xingwei Art \& Crafts factory (Xingwei), Sanyi Tie-and-Dye Industry \& Commercial Co. Ltd. (Sanyi), and Minzu Craft Clothing factory (Minzu).

Taking Xingwei as an example, a family operates the factory, and staff are locally recruited, who are knowledgeable 
on traditional tie-and-dye technology. According to informants, plant-based dyes are used in a few products; in 2016, up to $30 \%$ of total product was based on plant dyes. Products range from clothing to curtains, cushion cases, hats, handkerchiefs, napkin pads, and so on. Among these products, plant dyed ones are often sold to high-end product markets in Hongkong, Beijing, and Shanghai and exported to Japan, Korea, UK, and so on, while chemical dyed products are usually sold to domestic mass market.

Some limiting factors for commercialization of the plant dyes were identified after discussion at factories and informants. The main disadvantages are (1) the color fastness, which involves instability of dye, causing easy discoloration under conditions of water immersion, sweat stain, and sun exposure; (2) the production cost is higher than chemical dyeing because it is time consuming and labor intensive; and (3) the industrialized application of dye-yielding plants requires a large amount of raw material, which cannot be met solely by wild collection.

Regarding these issues, it is suggested that local governments should provide support for the research institutes as well as local universities to study the characteristics of different kinds of dyeing plants in practice, develop environment-friendly mordant to improve the color fastness of plant dyes, simplify dyeing method, reduce production cost, and adapt to mass production. Besides, it is crucial to establish their own ecological dyeing brand to accelerate the industrialization process and facilitate plant dyed products for a bigger market. Furthermore, we suggest formulation of policies (government and non-governmental organizations) to promote the supply of raw materials through local artificial cultivation and base planting.

\section{Conclusion}

As a traditional ethnic group that uses plant for dye, Bai in Dali Prefecture, Northwest Yunnan, China, owns unique knowledge on plant-based dye and has creatively developed many plant dyes. Our research documents 23 dye-yielding plant species belonging to 19 taxonomic families and selects three quantitative indicators-ICF, $f$, and $\mathrm{CI}-$ to evaluate the documented species. The findings highlight Bai's indigenous knowledge and practice of dyeing which includes three kinds of common plant dye making methods (water extraction, fermentation, and mashing), four dyeing methods (direct dyeing, pre-mordant dyeing, post-mordant dyeing, and co-bath dyeing), and tie-and-dye, the traditional craft of Bai people.

In summary, this study provides a deep understanding of Bai indigenous knowledge of dye-yielding plants. From the study, it can be concluded that there is need to in-depth research for the stability, safety, and functional ingredients of dye-yielding plants. Same time awareness about traditional importance of traditional textile dyeing, market-oriented research, and opportunity created for products that uses plant-based dye can support to conserve the traditional knowledge of plant-based dye and associated culture.

\section{Acknowledgements}

We gratefully thank the local people in DaLi and WeiShan, especially Mr. Renbiao Zhang, Mr. Wenjie Xiong, and Mr. Ming Li who assisted us with the valuable information. We also thank Dr. Sailesh Ranjitkar and Mr. Adejobi Oluwaniyi Isaiah for the revision of this article.

\section{Funding}

The project was funded by National Nature Science Foundation of China (31670340), the Ministry of environmental protection of China (Y61D031271), and Dr. Plant R\&D Center (Y65J8322C1).

Availability of data and materials

All data, materials, and information are collected from the study sites.

\section{Authors' contributions}

LXY and YXF conceived and designed the study. LXY funded this study. LXY, YXF, YQZ, LQL, and YKY conducted the field surveys and collected the data. $L X Y$ and $A Z L$ provided the plant species identification. YXF performed the literature review, analyzed the data, and wrote the manuscript. AH and LXY edited the manuscript. All authors read and approved the final manuscript.

Ethics approval and consent to participate

Not applicable.

\section{Consent for publication \\ Not applicable: this manuscript does not contain any individual personal data.}

\section{Competing interests}

The authors declare that they have no competing interests.

\section{Publisher's Note}

Springer Nature remains neutral with regard to jurisdictional claims in published maps and institutional affiliations.

\section{Author details}

${ }^{1}$ Southwest Forestry University, Kunming 650224, Yunnan, China. ${ }^{2}$ College of Forestry and Vocational Technology in Yunnan, Kunming 650224, Yunnan, China. ${ }^{3}$ Key Laboratory of Economic Plants and Biotechnology, Kunming Institute of Botany, Chinese Academy of Sciences, No. 132 Lanhei Road, Kunming 650201, China. ${ }^{4}$ Center for Biodiversity and Indigenous Knowledge, Kunming 650034, Yunnan, China.

Received: 11 August 2018 Accepted: 9 November 2018

Published online: 29 November 2018

\section{References}

1. Plácido J, Chanagá X, Ortiz-Monsalve S, Yepes M, Mora A. Degradation and detoxification of synthetic dyes and textile industry effluents by newly isolated Leptosphaerulina Sp. from Colombia. Bio B. 2016;3(1):6. https://doi. org/10.1186/s40643-016-0084-x.

2. ShadeeraRouf NM. Removal of harmful textile dye congo red from aqueous solution using chitosan and chitosan beads modified with CTAB. Int J Eng Sci. 2015;5(3):75-82.

3. Mujadžić S, Oros D, Kracher D, Pankiewicz N, Rezić I, Rezić T, Haltrich D, Ludwig R. Systematic degradation of synthetic dyes with heme and flavin containing oxidoreductases. Busse Collection. 2014;99:1055-7.

4. Shakeri A, Soheili V, Karimi M, Hosseininia SA, Fazly Bazzaz BSM. Biological activities of three natural plant pigments and their health benefits. J Food Meas Charact. 2018;12(1):356-61. https://doi.org/10.1007/s11694-017-9647-6.

5. Geng Y, Zhang Y, Ranjitkar S, Huai H, Wang Y. Traditional knowledge and its transmission of wild edibles used by the Naxi in Baidi Village, northwest 
Yunnan Province. J Ethnobiol Ethnomed. 2016;12(1):1-21. https://doi.org/10. 1186/s13002-016-0082-2.

6. Chai ZZ, Whang C, Wang YH. Field survey on the dyeing plants used by Dai people in Xishuangbanna. Guihaia. 2017;37(1):56-63. https://doi.org/10, 11931/guihaia.gxzw201603027.

7. Cui MK, Zhao WJ, Sun M, Zhu LJ. Ethnobotanical study on dye-yielding plants of the Buyi people: case study of Duoyi Village in Luoping County of Yunnan Province. J YNU(PSSE). 2011;31(4):21-5. https://doi.org/10.3969/j.issn. 1007-9793.2011.04.005

8. Chun YB, Li L. Survey on the growing environment of the main vegetable dyes in Guizhou minority area. J KU. 2014;32(6):46-9. https://doi.org/10. 3969/j.jssn.1673-9329.2014.06.14.

9. Su S, Ma B, Huang K, Xu Y. Ethnobotany study on dye-yielding plants of Zhuang people in the western Guangxi Province. Chin Sci Bull. 2013: 29(11):203-7.

10. Liu Y, Ahmed S, Liu B, Guo Z, Huang W, Wu X, Li S, Zhou J, Lei Q, Long C. Ethnobotany of dye plants in Dong communities of China. J Ethnobiol Ethnomed. 2014;10(1):23. https://doi.org/10.1186/1746-4269-10-23.

11. $\mathrm{Xu} \mathrm{J.} \mathrm{The} \mathrm{research} \mathrm{of} \mathrm{Li'} \mathrm{traditional} \mathrm{dyeing} \mathrm{technique} \mathrm{in} \mathrm{HaiNan,} \mathrm{China.}$ Nanjing: Nanjing University; 2014.

12. Tursunay A. Preliminary study of dyes of plant in Xinjiang, China. Urumqi: Xinjiang University; 2012

13. The population census office of the state council of China. Data of the 2010 census in China. Beijing: China Statistics Press; 2011.

14. Du K. A view of the origin, formation and designation of the Bai nationality. Ethno Stu. 1960;1:43-50.

15. Li DH. Viewing the origin of Bai nationality from archeological material. J MUC(PSSE). 2004;(1):72-8. https://doi.org/10.15970/j.cnki.1005-8575. 2004.01.013.

16. Zhu MJ. The aesthetic value and artistic features of Bai tie-and-dye pattern. Art Sci Technol. 2016;29(6):228. https://doi.org/10.3969/j.issn. 1004-9436.2016.06.196.

17. Shu FX. Chinese tie-and-dye art. China \& The World Cultural Exchange. 2010;2:80-3

18. Yan Y. The traditional process and pattern design of Dali Bai nationality tieand-dye. J MUC(NSE). 2017;26(2):61-4. https://doi.org/10.3969/j.issn.10058036.2017.02.010.

19. Ma Y. The education history of the Bai nationality. J MUC(PSSE). 1995;(2):64-5. https://doi.org/10.15970/j.cnki.1005-8575.1995.02.012.

20. Heckathorn DD. Snowball versus respondent-driven sampling. Socio Methodol. 2011;41:355-66. https://doi.org/10.1111/j.1467-9531.2011.01244.x.

21. Trotter RT, Logan MH. Informants consensus: a new approach for identifying potentially effective medicinal plants. Plants Indigenous Med Diet. 1986:91-112.

22. Lozada M. Nontimber forest product use in two human populations from northwest Patagonia: a quantitative approach. Hum Ecol. 2001;29(4):367-80. https://doi.org/10.1023/A:1013199103440.

23. Tardío J, Pardo-de-Santayana M. Cultural importance indices: a comparative analysis based on the useful wild plants of southern Cantabria (northern Spain). Econ Bot. 2008; 62(1):24-39. https://doi.org/ 10.1007/s12231-007-9004-5.

24. Zhang F. On the spread of "Bai Jie lady" image in Dali, China. Dali: Dali University; 2016.

25. Li RF. The torch festival of Bai people with collective representation-taking Bai Sha jing Village in Caojian, Dali, Yunnan for an example. Minority Art Studies. 2012;25(3):117-23. https://doi.org/10.14003/j.cnki.mzysyj.2012.03.006.

26. Jing SP. From tradition to modernity: tie-and-dye of Bai ethnic group in Zhou Cheng. Dali Ethnic Today. 2001;11:40-3.

27. Pu HL, Zhou H, Yu RJ, Wang J. Study on the extraction and properties of pigment from onion epidermis. Food Sci. 2002;23(5):43-5. https://doi.org/10, 3321/j.issn:1002-6630.2002.05.008.

28. Yang $X Z$, Yin $L M$, Yang YS. Determination of content of total flavones in Alnus ferdinandi-coburgii. J DU. 2013;12(12):9-11. https://doi.org/10.3969/j. issn.1672-2345.2013.12.003.

29. Oliveira FQ, Andrade-Neto V, Krettli AU, Brandão MGL. New evidences of antimalarial activity of Bidens pilosa roots extract correlated with polyacetylene and flavonoids. J Ethnopharmacol. 2004;93(1):39. https://doi. org/10.1016/j.jep.2004.03.026.

30. Yang SY, Zhuo WL, Lai YL, Fang XX, Chen XP, Yang N. Studies on the properties of yellow pigment from Buddleja officinalis Maxim. Food R D. 2014;35(4):19-22. https://doi.org/10.3969/j.issn.1005-6521.2014.04.005.
31. Badami S, Moorkoth S, Rai SR, Kannan E, Bhojraj S. Antioxidant activity of Caesalpinia sappan heartwood. Biol Pharm Bull. 2003;26(11):1534-7.

32. Lv HP. Analysis on the chemical compounds from Pu-er tea and their antioxidant activity. CAAS. 2005; https://doi.org/10.7666/d.Y756540.

33. Ma ZC, Terahara N. Study on the composition of pigments from Carthamus tinctorius flowers. China Food Additives. 2008;2:168-71 https://doi.org/10. 3969/j.issn.1006-2513.2008.02.041.

34. Geng ZP, Zheng HJ, Zhang Y, Luo WZ, Qu XY. Simultaneous determination of six alkaloids in Coptis Chinensis of different regions by RP-HPLC. Beijing: China J Chin Mater Med. 2010;35(19):2576-80. https://doi.org/10.4268/ cjcmm20101917.

35. Kamath S, Skeels M, Pai A. Significant differences in alkaloid content of Coptis Chinensis (huanglian), from its related American species. Chin MedUK. 2009;4(1):17. https://doi.org/10.1186/1749-8546-4-17.

36. Joshi BS. Phytochemical and antimicrobial screening of Coriaria nepalensis. J Oral Pathol Med. 2000;28(2):92-5.

37. Wang WG, Zhang QW, Zhao YL, Hu XW, Lin Q, Li JR, Wang W. Research progress on physical and chemical properties of natural pigments and their applications. J HUT(NSE). 2015;36(3):109-17. https://doi.org/10.16433/j.cnki. issn1673-2383.2015.03.021.

38. Fang EH, Li CY, Bear DH, Li GF. Determination of the main components of food additive curcumin and curcuma longa. China Food Additives. 2016;4: 155-60. https://doi.org/10.3969/j.issn.1006-2513.2016.04.017.

39. Zhou L, Xu M, Yang CR, Zhang YJ. Research progress on chemical constituents and bioactivities of fagaceae plants. Chengdu: Nat Prod Res Dev. 2012:24(2):260-73. https://doi.org/10.16333/j.1001-6880.2012.02.030.

40. Yan XY. Extraction and characterization of mopanshi persimmon fruit pigment. Beijing: China Agricultural-University; 2004. https://doi.org/10.7666/ d.649y659669.

41. Zhang $Y$, Yang $L, X f L$. Toxicity of pigment extracts from Eupatorium adenophorum. Li SZ Med Mater Medica Res. 2013;24(8):1900-2. https://doi. org/10.3969/j.issn.1008-0805.2013.08.041

42. Debnath T, Park PJ, Deb Nath NC, Samad NB, Park HW, Lim BO. Antioxidant activity of Gardenia jasminoides Ellis fruit extracts. Food Chem. 2011;128(3): 697-703. https://doi.org/10.1016/j.foodchem.2011.03.090

43. Wang JT. Research advance on natural hibiscetin red pigment. Cereals Oils. 2010:11:40-3 https://doi.org/10.3969/j.issn.1008-9578.2010.11.013.

44. Sakunphueak A, Panichayupakaranant P. Comparison of antimicrobial activities of naphthoquinones from Impatiens balsamina. Nat Prod Res. 2012; 26(12):1119-24. https://doi.org/10.1080/14786419.2010.551297.

45. Zhong JM. Activity of ingredients of walnut green husk pigment extraction and its application research. Urumqi: Xinjiang University; 2014.

46. Li XL, Li JY, Fan ZQ, XuY L, Liang QY. Components of pigments of Morus alba and Myrica rubra fruits. Acta Agric Shanghai. 2013. https://doi.org/10. 3969/j.issn.1000-3924.2013.05.023.

47. Yu ZC, Yang B, Zhou B. Study on the stability of Onosma paniculatum pigment and its dyeing properties on wool. Wool Textile J. 2003;2(4):14-6. https://doi.org/10.19333/..mfki.2003.02.004

48. Hu WH, Xie Q, Dong RZ, Zhang YL, Li FH. Study on the extraction of yellow pigment from pomegranate peel and its physicochemical properties. Sci Technol Food Indust. 2001;6:26-7. https://doi.org/10.13386/j.issn1002-0306. 2001.06.009.

49. Li XM, Wang W, Dai JH, Gao LB, Yuan ML, Sun WQ, Zeng XL, Huang XZ. Studies on the barks of Quercus acutissima Carruth. J YMU(NSE). 2015;24(2): 104-7. https://doi.org/10.3969/j.issn.1672-8513.2015.02.005.

50. Li HF, Xiao LY, Zhang J, Wang HH, Han WJ, Huang ZB. Research progress on chemical constituents and pharmacological effects of madder. Guangzhou: J Chin Med Mate. 2016;39(6):1433-6. https://doi.org/10.13863/j.issn10014454.2016.06.058.

51. Chang HN, Huang ST, Yeh YC, Wang HS, Wang TH, Wu YH, Pang JHS. Indigo naturalis and its component tryptanthrin exert anti-angiogenic effect by arresting cell cycle and inhibiting Akt and FAK signaling in human vascular endothelial cells. J Ethnopharmacol. 2015;174:474-81. https://doi.org/10. 1016/j.jep.2015.08.050

52. Li HM. Research progress on the diversity and application of natural dyeing plants. J XPU. 2006;20(3):378-82. https://doi.org/10.13338/j.issn.1674-649x. 2006.03.029. 